\title{
Quantifying physical and structural soil properties using X-ray microtomography
}

\author{
Chien Ling Tseng ${ }^{\mathrm{a}, *}$, Marlene Cristina Alves ${ }^{\mathrm{b}}$, Silvio Crestana ${ }^{\mathrm{c}}$ \\ ${ }^{a}$ University of São Paulo (USP), São Carlos School of Engineering, 400 Avenida Trabalhador São-carlense, CEP: 13566-590 São Carlos, São Paulo, Brazil \\ b Paulista State University (UNESP), 56 Avenida Brasil, Centro, CEP: 15385-000 Ilha Solteira, São Paulo, Brazil \\ ${ }^{\mathrm{c}}$ Embrapa Instrumentation, 1452, Rua XV de Novembro, CEP: 13560-970 São Carlos, São Paulo, Brazil
}

\section{A R T I C L E I N F O}

Handling Editor: Morgan Cristine L.S.

Keywords:

Microtomography

$\mathrm{S}$ index

Degree of anisotropy

Euler-Poincaré number

Shannon entropy

3D simulation

\begin{abstract}
A B S T R A C T
One of the current challenges in the study of recovering soil architecture is physically evaluating the internal soil structure in unconventional ways. The elaboration of consistent methods and physical parameters has become necessary for soil structural analysis. The aim of this study is to analyze the soil structures of two groups of recovering tropical soils and to simulate three-dimensional water movement pathways using unconventional methods and physical soil parameters. The following results were obtained from the analysis: 1) the S index was used as an indicator to effectively quantify the degree of management; 2) Qualisolo software was used to obtain the soil water retention curve (SWRC) of each management type; 3 ) the degree of anisotropy of the solid structure reflected the soil network; 4) the Euler-Poincaré number reflected the connectivity of the soil pores for each management type; 5) the Shannon entropy indicated the degree of randomness of the soil; and 6) the results of the Arya and Paris model and the simulations of water movement pathways are similar. In conclusion, the obtained results reflect the internal soil structures and their corresponding characteristics. Thus, the results can be used to predict the influence of soil architecture on the movement of water in the soil.
\end{abstract}

\section{Introduction}

The Brazilian cerrado (Savannah) biome is important for food and agricultural production due to its soil and climate. However, the cerrado soil has been intensively devastated by human activities over the past decade, and these activities have threatened sustainable resource use in the region. In this context, recovering degraded areas is important for ensuring sustainable soil use. However, determining how to evaluate the physical architecture of the recovering tropical soil and preserving its internal structure remains a challenge in evaluating this resource.

Among several minimally invasive and unconventional techniques and methods, X-ray computerized tomography (XCT) has become a common method for studying soil structure in recent decades. Petrovic et al. (1982), Hainsworth and Aylmore (1983) and Crestana et al. (1985) pioneered XCT methods for studies of soil density and measured the water content and water movement into the soil. Additionally, Appoloni and Cesareo (1994) performed microscanning and microtomography using an X-ray tube.

Although XCT has become popular in recent decades, applying it to tropical soils remains uncommon in the literature. Nevertheless, given the scarcity of related papers, some important tropical soil research using XCT should be highlighted. Vaz et al. (2011) evaluated two Brazilian Oxisols and established the scanning parameters for the soil. Passoni et al. (2014) characterized the soil macroporosity of a Rhodic Ferralsol using a second-generation X-ray microtomograph. In addition, Beraldo et al. (2014) used microtomography to quantify the porosity in areas with no tillage practices, conventional tillage practices and native forest. Recently, Marchini et al. (2015) applied CT to study recovering Brazilian Oxisols from the soil at $8.6 \mathrm{~m}$ deep, which has been exposed since the sixties, under different types of management strategies. Furthermore, Marchini et al. (2015) qualitatively evaluated recovering tropical soil under different management strategies using microtomography.

Thus, XCT could be used to develop indicators that can directly quantify soil internal structures using images, which would preserve the original soil. We selected 2 conventional and 5 unconventional physical parameters to characterize the differences in soil internal structures under different management types: bulk density, total porosity, soil water retention curve (SWRC), S index (Dexter, 2004), degree of anisotropy, Euler-Poincaré number and Shannon entropy. In addition, this study provides a two-dimensional visualization of the soil and

\footnotetext{
* Corresponding author.

E-mail addresses: chienlt86@86sc.usp.br (C.L. Tseng), mcalves@agr.feis.unesp.br (M.C. Alves), silvio.crestana@embrapa.br (S. Crestana).
} 
associated parameters and simulates water movement pathways in three dimensions. This approach can be used to visualize the recovery of soil structure under different management strategies at the pore level and to predict the behavior of water in the soil under different management types.

The capacity of soil to retain water is manifested in the SWRC, which is typically determined using methods that involve a funnel with a porous plate, tension table or pressure plate apparatus in the laboratory. In the field, different combinations of methods are used, e.g., a tensiometer is connected with a mercury manometer to determinate the water potential $(\Psi)$, while time-domain reflectometry (TDR) and gravimetry are used to determine the volumetric soil moisture (Manieri et al., 2007). Due to the difficulty of experimentally obtaining SWRC, it is necessary to develop an indirect method to estimate SWRC, such as pedotransfer functions (PTFs) (Tomasella et al., 2000) and the Arya and Paris model, which was validated by Vaz et al. (2005) using 104 samples from the main soil class in Brazil.

The $S$ index (soil physical quality) is obtained from the slope at the inflection point of the SWRC, which represents the relationship between the water content and the soil water potential, and is treated as a structural slope based on the pore distribution. Several important physical soil properties can be directly estimated using the $S$ index (Dexter, 2004). For example, Varandas (2011) showed that the S index provides a quantitative measure to describe the soil degradation status with other parameters. However, there is controversy in the literature about applying the $\mathrm{S}$ index as a soil physical quality. For instance, van Lier (2014) stated that the $S$ index assumes a unimodal distribution of pore radii, so it does not have additional value over the bulk density and is not capable of predicting the soil physical quality alone. Zeviani (2013) mathematically detailed the bimodal pore distribution using the SWRC, and Carducci et al. (2013) associated the S index with the adopted management system, i.e., as a structural quality indicator. Therefore, in addition to the $\mathrm{S}$ index, we consider all of the soil structural quality indicators, according to Moncada et al. (2015).

In this study, we used Qualisolo software (Naime et al., 2001), which applies the van Genuchten (1980) equation that was adjusted by the Arya and Paris (1981) model to obtain the SWRC and S index. In addition, this software was satisfactorily validated, which allows for analyzing a large quantity of samples in a short time that is impractical when using conventional methods (Vaz et al., 2005). In addition, the SWRC provided the permanent wilting point $\left(\theta_{\mathrm{pmp}}\right)$, field capacity $\left(\theta_{\mathrm{cc}}\right)$ and available water capacity (AWC) for each management system.

The degree of anisotropy strongly reflects the orientation of the elements inside a determined volume (Odgaard, 1997); thus, it influences the flux characteristics in a porous medium (Hernández Zubeldia et al., 2015). Bottinelli et al. (2016) demonstrated the stability of the degree of anisotropy in the formation of macropores during shrinkage in rice-cultivated soils.

The Euler-Poincaré number is a fundamental parameter that describes the connectivity of spatial structures (Vogel, 1997; Vogel and Roth, 2001). Recently, Martínez et al. (2015) used this parameter to study the geometry of aggregated soil; they concluded that this metric is capable of clearly reflecting the pattern of aggregates associated with different management types. Additionally, Katuwal et al. (2015) used a case study to show that this parameter is inadequate when isolated connections are predominant.

The next physical parameter is Shannon (2001) entropy, although this parameter is seldom included in soil analyses. Nevertheless, Gaur and Mohanty (2013) showed that Shannon entropy can be applied to understand the dominant physical control of spatiotemporal variability in soil moisture.

Applying the percolation theory in porous media involves the inclusion of random properties (Berkowitz and Ewing, 1998). For example, a study on the fingering phenomenon used a modified invasion percolation model (Onody et al., 1995). This study used an open source program published by Nakashima and Kamiya (2007) to simulate the transport properties inside the pores through three-dimensional microtomography, thus providing a visualization of water pathways in the soil under dry conditions. Such studies are important for evaluating management strategies and soil quality under various conditions.

The objective of this study is to apply unconventional methods and physical soil parameters to analyze the soil structures of two groups of recovering tropical soils and to predict the water movement pathways in three dimensions by using tomography.

\section{Materials and methods}

\subsection{Experimental sites}

The soil samples were obtained at Fazenda de Ensino e Pesquisa da Universidade Estadual Paulista "Júlio de Mesquita Filho" (Unesp) (Teaching and Research Farm of Paulista State University "Júlio de Mesquita Filho") at the Ilha Solteira campus in the city of Selvíria (Mato Grosso do Sul State - Brazil). This area is located on the banks of the Paraná River $\left(22^{\circ} 22^{\prime} \mathrm{S}\right.$ and $\left.51^{\circ} 22^{\prime} \mathrm{W}\right)$. Due to the construction of a hydroelectric power station at Ilha Solteira (São Paulo State) in 1969, subsoil containing the $\mathrm{B}$ horizon has remained exposed and has exhibited severe superficial compaction and a low presence of vegetation. The soil in the experimental area is a dystrophic Red Latosol characterized by advanced stages of weathering (Embrapa Solos, 2013).

\subsection{Management description}

The experiment implemented in this study included six management strategies, which were divided into two groups according to their texture similarity. Group I includes 1) soil from the native forest (Brazilian Savannah); 2) recovered soil (soil that had green manure applied over seven years from 1992 to 1999 and was then cultivated with Brachiaria decumbens); 3) recovering soil with Astronium fraxinifolium (Gonçaloalves) + Brachiaria decumbens + sewage sludge; and 4) degraded soil (remaining soil from the construction of the hydroelectric power plant). Group II includes 5) recovering pasture soil and 6) degraded pasture soil. All samples were collected from the superficial layer $(0-10 \mathrm{~cm})$.

\subsection{Physical analysis}

In this study, the sampling analysis was based on microtomography instead of a field sampling campaign. The sample for microtomograph was collected with an acrylic tube to minimize image artifact and was always extracted from the upper side of an undisturbed block.

\subsubsection{X-ray microtomography and image reconstruction}

The commercial, high-resolution X-ray microtomograph and NRCon software (NRCon User Manual, 2016) from Embrapa Instrumentation were used to acquire and reconstruct tomographic images, respectively. The spatial resolution of the images was $4.96 \mu \mathrm{m}$, and the reconstruction parameters were adjusted according to Vaz et al. (2011).

To perform the statistical calculations, 500 images of $1000 \times 1000$ pixels were appropriately treated for each management type. Initially, the images were binarized using the Otsu (1975) method, which minimizes the sum of variances between image classes and the background. Second, CT-Analyser (2013) software was used to calculate the Euler-Poincaré number and the degree of anisotropy as both parameters are three-dimensional and do not have units. In addition, the same images were used in three-dimensional simulations. Except for the Shannon entropy, only one representative image was selected for each management type using the 'entropy' package in $\mathrm{R}$ (Hausser et al., 2012), a free software environment for statistical computing and graphics. This software was employed in this study due to the considerable amount of information contained in each image. 


\subsubsection{SWRC and the $S$ index}

The soil analysis in the laboratory was performed using three replicates of $40 \mathrm{~g}$ for each management type, and samples were processed using an automatic particle size analyzer and Qualisolo software (Naime et al., 2004). The SWRC and S index were estimated for each management type, and the built-in equations in the software were previously validated for use in analyzing Brazilian soils (Andrade and Stone, 2009; Vaz et al., 2005). These variables were calculated in two steps, as described below. The average of three replicates for each management type was obtained from the results of these steps.

First, the SWRC was produced from the granulometry data provided by the particle size analyzer, which was previously validated by using the pipette method in a conventional laboratory test (Macedo, 2003) and the Arya and Paris model (Vaz et al., 2005). The model equation is described as follows:

$$
\Psi_{i}=\frac{2 \sigma}{\rho_{\mathrm{w}} g R_{\mathrm{i}} \sqrt{\frac{2 \rho_{\mathrm{p}}-\rho_{\mathrm{s}}}{3 \rho_{\mathrm{s}}}\left(\frac{3 \mathrm{w}_{\mathrm{i}}}{4 \pi \mathrm{R}_{\mathrm{i}}^{3} \rho_{\mathrm{p}}}\right)^{1-\alpha}}}
$$

where $\Psi_{\mathrm{i}}$ is the soil matric potential, which is found based on the inverse form of the van Genuchten (1980) equation; $\alpha$ is a scaling factor determined experimentally for Brazilian soil; $\rho_{\mathrm{w}}$ is water density $\left(\mathrm{kg} \mathrm{m}^{-3}\right) ; \mathrm{g}$ is the acceleration of gravity $\left(\mathrm{m} \cdot \mathrm{s}^{-2}\right) ; \mathrm{R}_{\mathrm{i}}$ is the particle radius; $\rho_{\mathrm{p}}$ is the soil particle density $\left(\mathrm{kg} \mathrm{m}^{-3}\right) ; \rho_{\mathrm{s}}$ is the soil bulk density $\left(\mathrm{kg} \mathrm{m}^{-3}\right)$; and $\mathrm{w}_{\mathrm{i}}$ is the soil mass of the $\mathrm{i}^{\text {th }}$ fraction, which is calculated via fitting a sigmoidal model to cumulative particle size distribution data.

Additionally, the particle radius was derived from the soil pore radius $\left(\mathrm{r}_{\mathrm{i}}\right)$, considering the packaging of spherical particle and a scaling value, which corrects the estimated structured soil by Eq. (2):

$r_{i}=R_{i} \sqrt{\frac{4 e n_{i}^{1-\alpha}}{6}}$

$\mathrm{n}_{\mathrm{i}}$ is the particle tax number of class $\mathrm{i}$; e is pore volume/particle volume according to Arya and Paris (1981) fitted to Brazilian soil (Vaz et al., 2003).

The same SWRC adjusted based on the van Genuchten (1980) equation and Arya and Paris (1981) model (Vaz et al., 2005) was used to obtain the S index (Dexter, 2004). The S index corresponds to the angular coefficient or slope of the tangent at the inflection point of the SWRC, as expressed by Eq. (3):

$\mathrm{S}=-\mathrm{n}\left(\theta_{\mathrm{s}}-\theta_{\mathrm{r}}\right)\left[1+\frac{1}{\mathrm{~m}}\right]^{-(1+\mathrm{m})}$

where $S$ is the slope of the SWRC at its inflection point; $n$ and $m(1-1 / n)$ are empirical parameters in the van Genuchten (1980) equation; and $\theta_{s}$ and $\theta_{\mathrm{r}}$ are the saturated and residual soil water contents $\left(\mathrm{kg} \mathrm{kg}^{-1}\right)$, respectively. When the $S$ index reference value is $\leq 0.020$, its physical structure quality is very poor; when the value is $>0.020$ and $=0.035$, the physical structure quality is poor; and when the value is $>0.035$, the physical structure quality is good.

From the SWRC, we also estimate $\theta_{\mathrm{pmp}}, \theta_{\mathrm{cc}}$ and AWC based on the equations below:

$\theta_{\text {pmp }}=\left(\theta_{\mathrm{r}}+\left(\theta_{\mathrm{s}}-\theta_{\mathrm{r}}\right) \times\left(\left(\left(\frac{1}{(1+(\alpha \times 1500}\right)^{\mathrm{n}}\right)^{\frac{\mathrm{n}-1}{\mathrm{n}}}\right) \times \mathrm{d}_{\mathrm{g}}\right.$

$\theta_{\mathrm{cc}}=\left(\theta_{\mathrm{r}}+\left(\theta_{\mathrm{s}}-\theta_{\mathrm{r}}\right) \times\left(\left(\left(\frac{1}{(1+(\alpha \times 100}\right)^{\mathrm{n}}\right)^{\frac{\mathrm{n}-1}{\mathrm{n}}}\right) \times \mathrm{d}_{\mathrm{g}}\right.$

$\mathrm{AWC}=\theta_{\mathrm{cc}}-\theta_{\mathrm{pmp}}$

where $\theta_{\text {pmp }}$ is the permanent wilting point; $\theta_{\mathrm{s}}$ and $\theta_{\mathrm{r}}$ are the saturated and residual soil water contents $\left(\mathrm{kg} \mathrm{kg}^{-1}\right)$, respectively; $\sigma$ is a scaling

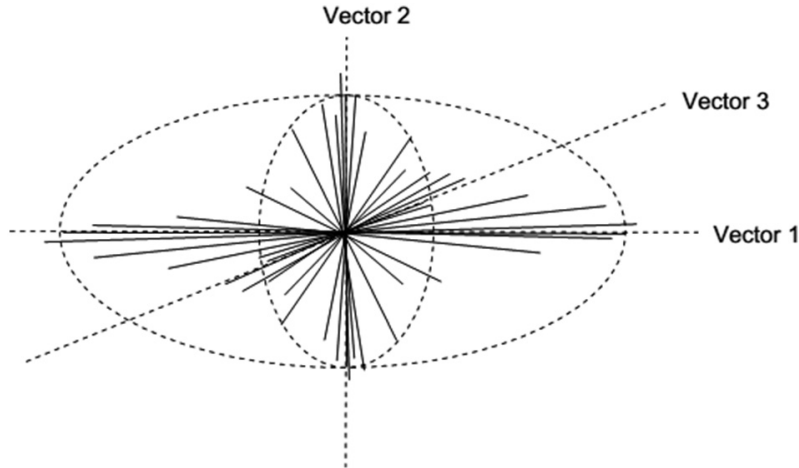

Fig. 1. An ellipsoid is statistically inserted in the 3D distribution of the MIL with the three orthogonal vectors between them, forming a tensor of 9 eigenvectors. (Adapted from Skyscan, 2015).

factor determined experimentally for Brazilian soil; $\mathrm{n}$ is an empirical parameter in the van Genuchten (1980) equation; $d_{g}$ is the bulk density; $\theta_{\mathrm{cc}}$ is the field capacity; and AWC is the available water capacity.

\subsubsection{Degree of anisotropy}

The mean intercept length is a variable used to indicate how directionally dependent the pores are based on the eigenvalues used to calculate the degree of anisotropy. A series of vectors (w) originate from the center of the volume and are then divided by the number of times they intercept the porous or solid parts of the volume. To obtain the degree of anisotropy in 3D, the mean intercept length distribution is described using an ellipsoid structure according to three axes in tensor form (Harrigan and Mann, 1984) (Fig. 1).

Each tensor is derived from the degree of anisotropy and is a function of the eigenvalues. The expression of the degree of anisotropy calculated using the CT-Analyzer is given in Eq. (7):

Degree of anisotropy $=\left(1-\left[\frac{\text { Min·eigenvalous }}{\text { Max.eigenvalous }}\right]\right)$

where a value of 1 is considered completely anisotropic and 0 is isotropic (Skyscan, 2015).

\subsubsection{Euler-Poincaré number}

The Euler-Poincaré number $(\chi)$ is a connectivity indicator of the object X structure in three dimensions. This metric is used to characterize the connections in a structure before it is separated into two parts. The basic topological properties of the Euler-Poincaré number of a 3D object $\mathrm{X}$ include the number of objects (pores) $\left(\beta_{0}\right)$, the connectivity $\left(\beta_{1}\right)$, and the number of enclosed cavities $\left(\beta_{2}\right)$. Therefore, the $3 \mathrm{D}$ components used in the CT-Analyzer software are as follows (Vogel, 2002; Katuwal et al., 2015 and Skyscan, 2015):

$\chi(X)=\beta_{0}-\beta_{1}+\beta_{2}$

According to Rozenbaum et al. (2012), the higher the Euler-Poincaré number is, the lower the connectivity; $\beta_{0}>\beta_{1}$ in these cases. When this number has a negative value $\left(\beta_{0}<\beta_{1}\right)$, the connectivity of the porous structure will be higher than that with a positive value. Notably, the $\beta_{2}$ value is not important for a network of natural pores because it is rare to find solid particles completely surrounded by porous spaces (Vogel, 2002).

\subsubsection{Shannon entropy}

To calculate the Shannon entropy, one image was preselected from the middle of each sample. Each image consisted of $1000 \times 1000$ pixels. Then, the expected value of information is determined based on each image (Wu et al., 2013). This approach describes the disorder related to the management of the soil. The definition of entropy is given by Brunsell (2010): 
$\mathrm{H}(\mathrm{x})=-\sum_{\mathrm{i}=1}^{\mathrm{n}} \mathrm{p}\left(\mathrm{x}_{\mathrm{i}}\right) \log \left(\mathrm{p}\left(\mathrm{x}_{\mathrm{i}}\right)\right)$

where $p_{i}$ is the probability density function of variable $x$ with bin $i$. The higher the value of $\mathrm{H}(\mathrm{x})$ is, the lower the entropy will be, and vice versa, i.e., entropy reflects the degree of soil management randomness.

Thereby, the maximum likelihood (ML) estimator was used to calculate $\mathrm{H}(\mathrm{x})$ for each tomographic image. The ML principle is based on a set of random variables $X_{n}$, which is related to the probability distribution $\mathrm{P}(\mathrm{x} \mid \phi)$, where $\mathrm{x}$ is a vector in the sample and $\phi$ is a spatial parameter. The principle of ML is to select the value of $\phi$ that maximizes $\mathrm{P}(\mathrm{x} \mid \phi)$ based on observations. In other words, the ML estimator seeks to find the frequency of each level of grayscale that appears in the image and determines the $\mathrm{H}(\mathrm{x})$ value of the Shannon entropy of the system.

\subsubsection{Visualization of the soil plane and three-dimensional simulation}

This portion of the qualitative study was divided into two visualization parts. The sample orientation was always tagged according to field condition. In the first part, the soil plane structure was analyzed using two-dimensional microtomography to visualize and assess each management type. DataViewer software, which was developed by Bruker microCT, was used to divide the image into three different planes: transverse (an imaginary plane that divides object into superior and inferior parts), coronal (ventral and dorsal parts) and sagittal (right and left parts) planes. We selected 9 slices in total from the top to bottom (transversal) and 9 slices from ventral to dorsal (coronal) to perform qualitative analysis and then represented each management by the middle slice. Because the coronal and sagittal plane are similar, we chose to analyze only the coronal plane.

In the second part, 3D pathways of water movement in the soil were simulated using Mathematica 5.2. This portion of the analysis consisted of three parts (Nakashima and Nakano, 2012): 1) Itrimmin.nb - selects and segments the region of interest (ROI) of the tomography; 2) Clabel.nb - classifies the porous area of the image, which is essential for investigating the random movement (walk) of fluid molecules through the pores; and 3) Rwalk.nb - simulates the random diffusion of nonsorbing elements within the pores in three dimensions. The main output of Rwalk.nb is the mean square displacement, $\left\langle\mathrm{r}^{2}\right\rangle$, which is based on dimensionless integer time, $\tau$, as demonstrated in Eq. (6), and plots of the displacement of the walkers along three axes in Cartesian coordinates (Nakashima and Kamiya, 2007):

$\left\langle\mathrm{r}(\tau)^{2}\right\rangle=\frac{1}{\mathrm{n}} \sum_{\mathrm{i}=1}^{\mathrm{n}}\left[\left(\mathrm{x}_{\mathrm{i}}(\tau)-\mathrm{x}_{\mathrm{i}}(0)\right)^{2}+\left(\mathrm{y}_{\mathrm{i}}(\tau)-\mathrm{y}_{\mathrm{i}}(0)\right)^{2}+\left(\mathrm{z}_{\mathrm{i}}(\tau)-\mathrm{zx}_{\mathrm{i}}(0)\right)^{2}\right]$

\section{Results and discussion}

\subsection{SWRC and the $S$ index}

The $S$ index was used as one more indicator to describe the soil structure status in this study and, in parallel, we provide the values of bulk density and total porosity for each management strategy to strengthen the result.

Group I (Table 1): Soil from the native forest exhibited the best $S$ index value and represents a standard sample of natural soil conditions. In the laboratory, soil from the native forest exhibited higher total porosity and lower soil bulk density than soil from other management types; therefore, soil from the native forest soil is assumed to represent good physical quality. The $\mathrm{S}$ index of recovered soil is closest to that of soil from the native forest among all the samples; however, recovered soil was not associated with good physical quality according to the reference values. The results
Table 1

$\mathrm{S}$ index for Group I management types.

\begin{tabular}{lllll}
\hline Types of management & $\begin{array}{l}\text { Soil from } \\
\text { native } \\
\text { forest }\end{array}$ & $\begin{array}{l}\text { Recovered } \\
\text { soil }\end{array}$ & $\begin{array}{l}\text { Recovering } \\
\text { soil }\end{array}$ & $\begin{array}{l}\text { Degraded } \\
\text { soil }\end{array}$ \\
\hline S index & 0.036 & 0.024 & 0.019 & 0.017 \\
Bulk density $\left(\mathrm{g} \mathrm{cm}^{-3}\right)$ & 1.23 & 1.45 & 1.58 & $\begin{array}{l}1.61 \\
\text { Total porosity (\%) }\end{array}$ \\
\hline 55.35 & 47.28 & 42.15 & 41.68 \\
\hline
\end{tabular}

suggest that the recuperation process has had positive effects. The $\mathrm{S}$ index of recovering soil is between that of recovered soil and that of degraded soil; therefore, although recovering soil exhibited improvements in total porosity and soil bulk density, this management type is still similar to degraded soil, which is poor in terms of physical structural quality.

Recovered soil had the closest $\theta$ value to soil from the native forest than the other soil samples (Fig. 2a). Thus, the recovered soil structural quality was similar to that of natural conditions and positive from the perspective of land use. Moreover, recovering soil was almost identical to degraded soil due to its compaction characteristics; however, recovering soil is more likely to display long-term improvement.

Group II (Table 2): The soil structural quality of recovering pasture soil and degraded pasture soil remained poor; however, that of recovering pasture soil was slightly better than that of degraded pasture soil. Notably, the recovery techniques applied in the area had a positive effect on the structural quality, which should improve over time.

Similarly, the SWRC differences between soil from the native forest and recovering pasture soil and degraded pasture soil (Fig. 2b) suggest that the structural quality of soil from the native forest is much better than that of recovering pasture soil and degraded pasture soil. These soil types are extremely compacted because of poor management in pasture areas.

\subsection{Degree of anisotropy}

The degree of anisotropy indicates similar spatial characteristics in all four directions in the image; this physical parameter influences the flux behavior in the saturated soil (Hernández Zubeldia et al., 2015). In other words, the magnitude and direction of infiltration is dependent on the degree of anisotropy, as a consequence of the anisotropy, which have been cited as follows: flow direction, flow tube convergence and soil development, hydrology of watersheds, surface runoff, erosion and miscellaneous effects related to the infiltration process (Zaslavsky and Rogowski, 1969). For now, we focus only on the relation between degree of anisotropy and infiltration direction. When the value of degree of anisotropy is close to 1 , the medium is fully anisotropic, i.e., the tendency for the infiltration direction tends to become almost parallel to the soil surface. When the value is 0 , the medium is uniform and isotropic, and infiltration is vertical.

Group I (Fig. 3a): The degree of anisotropy of degraded soil and recovering soil are high, suggesting that these soils are more anisotropic than soil from the native forest and recovered soil. Thus, the infiltration direction should assume to be parallel to the soil surface, i.e., susceptible to erosion, unlike the soil from the native forest and recovered soil, which are more isotropic, with infiltration that tends to become vertical. Notably, recovered soil and soil from the native forest exhibit similar physical structural qualities, i.e., both are favorable to water flux at the microscale. Recovering soil is highly compacted and has similar characteristics to degraded soil; 


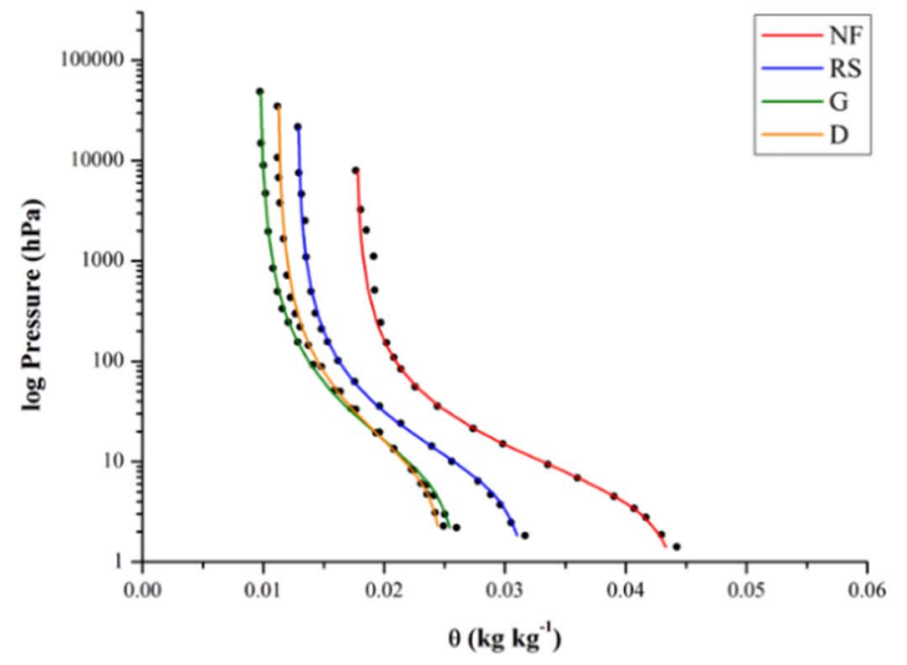

a

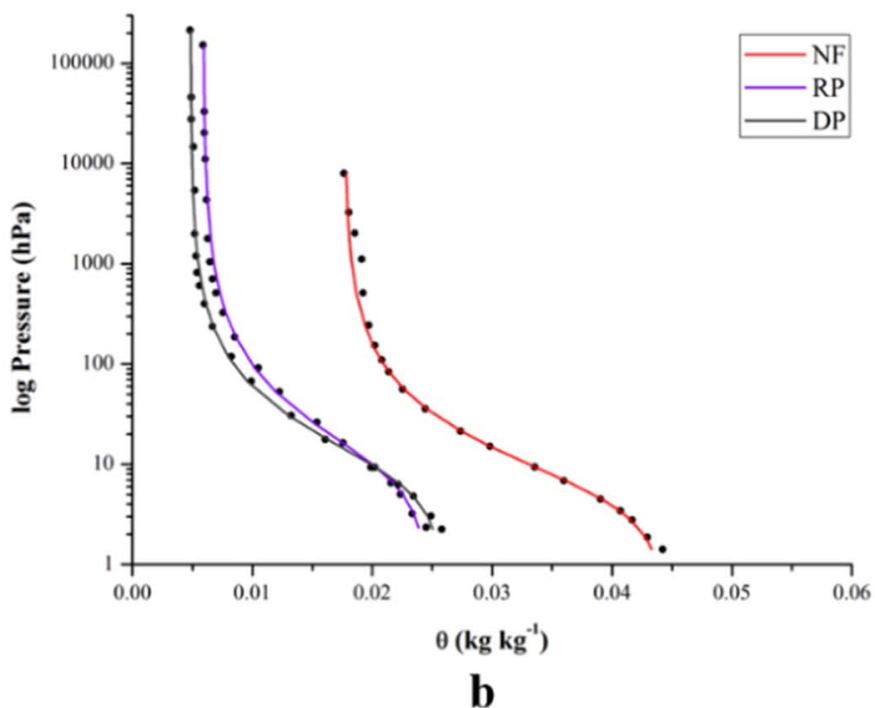

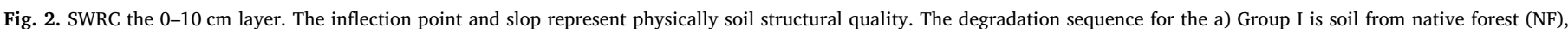

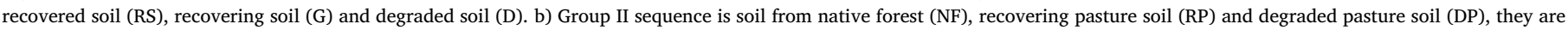
correspondents to the real situation.

Table 2

$\mathrm{S}$ index for Group II management types.

\begin{tabular}{llll}
\hline $\begin{array}{l}\text { Types of } \\
\text { management }\end{array}$ & $\begin{array}{l}\text { Soil from } \\
\text { native forest }\end{array}$ & $\begin{array}{l}\text { Recovering pasture } \\
\text { soil }\end{array}$ & $\begin{array}{l}\text { Degraded pasture } \\
\text { soil }\end{array}$ \\
\hline $\begin{array}{l}\text { S index } \\
\text { Bulk density } \\
\quad\left(\mathrm{g} \mathrm{cm}^{-3}\right)\end{array}$ & $\begin{array}{l}0.036 \\
1.23\end{array}$ & $\begin{array}{l}0.024 \\
1.61\end{array}$ & $\begin{array}{l}0.029 \\
1.56\end{array}$ \\
Total porosity (\%) & 55.35 & 39.56 & 41.72 \\
\hline
\end{tabular}

moreover, their residual and saturated soil water contents $\left(\theta_{\mathrm{r}}\right.$ and $\left.\theta_{\mathrm{s}}\right)$ were similar (Table 3 ) due to the scarcity of vegetation cover. Soil from the native forest and recovered soil, which have more dense vegetation cover, present high values of saturated and residual water (Table 3).

Group II (Fig. 3b): Soil from forest native and recovering pasture soil have similar values, representing a positive structural recovery processes. In terms of anisotropy, these soils are slightly more anisotropic than degraded pasture soil, i.e., the infiltration direction tends to be more horizontal than that of degraded pasture. Degraded pasture soil tends to be uniform and isotropic, thus resulting in
Table 3

Residual and saturated wetness $\left(\theta_{\mathrm{r}}\right.$ and $\left.\theta_{\mathrm{s}}\right)$ of Group I.

\begin{tabular}{lllll}
\hline $\begin{array}{l}\text { Type of } \\
\text { management }\end{array}$ & $\begin{array}{l}\text { Soil from } \\
\text { native } \\
\text { forest }\end{array}$ & Recovered soil & Recovering soil & Degraded soil \\
\hline$\theta_{\mathrm{r}}$ & 0.24 & 0.15 & 0.11 & 0.10 \\
$\theta_{\mathrm{s}}$ & 0.45 & 0.32 & 0.27 & 0.25 \\
\hline
\end{tabular}

Table 4

Residual and saturated wetness $\left(\theta_{\mathrm{r}}\right.$ and $\left.\theta_{\mathrm{s}}\right)$ of Group II.

\begin{tabular}{llll}
\hline Type of management & $\begin{array}{l}\text { Soil from } \\
\text { native forest }\end{array}$ & $\begin{array}{l}\text { Recovering pasture } \\
\text { soil }\end{array}$ & $\begin{array}{l}\text { Degraded pasture } \\
\text { soil }\end{array}$ \\
\hline$\theta_{\mathrm{r}}$ & 0.24 & 0.04 & 0.06 \\
$\theta_{\mathrm{S}}$ & 0.45 & 0.25 & 0.26 \\
\hline
\end{tabular}

vertical infiltration flux. However, the recovering and degraded pasture soil have similar residual and saturated water contents (Table 4). This similarity is related to the soil structure and

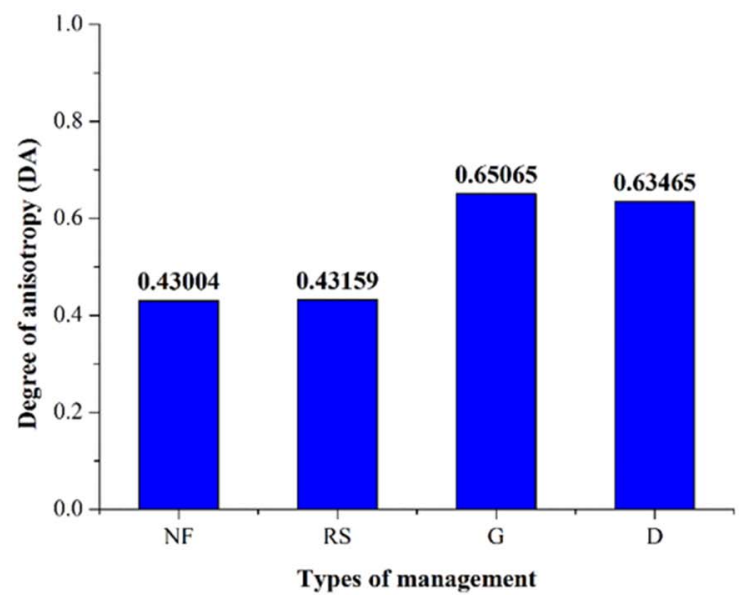

a

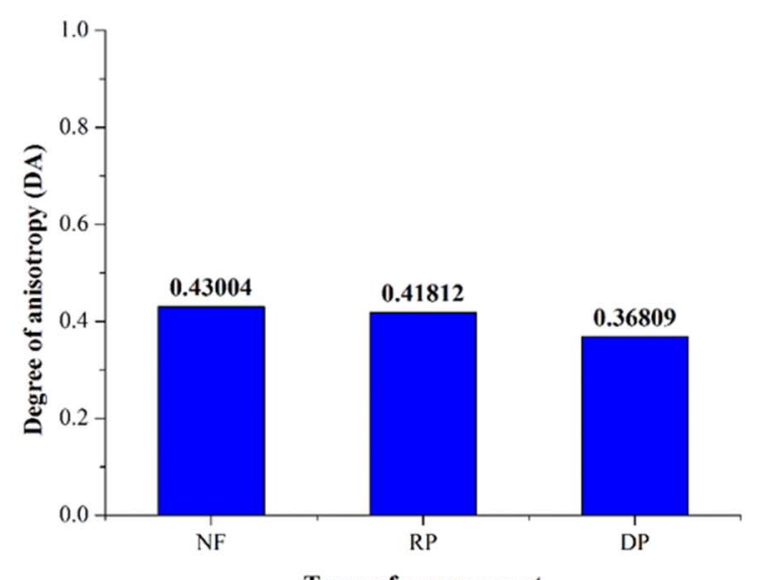

Types of management

b

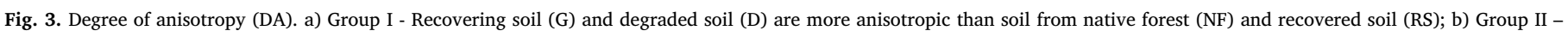
Recovering pasture soil (RP) is considerable close to soil from native forest (NF). Degraded pasture (DP) soil demonstrates be isotropic. 


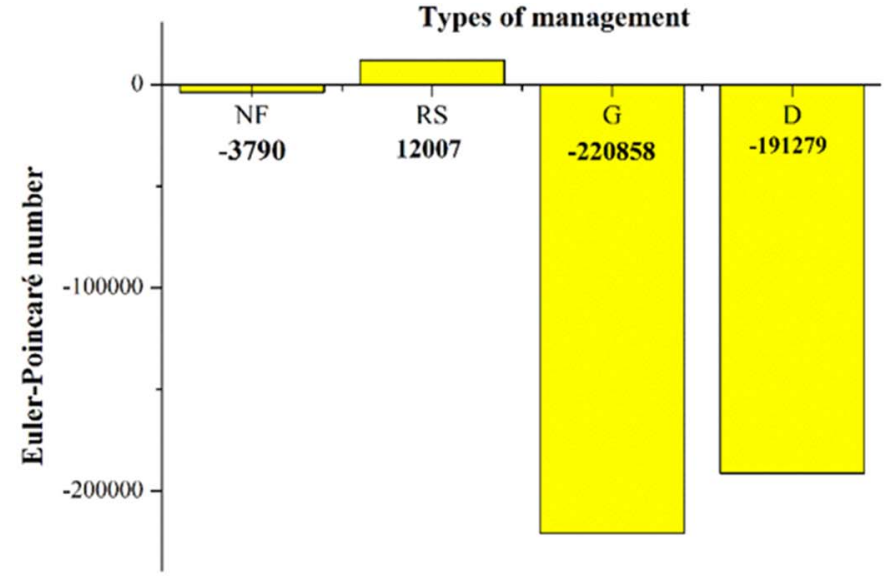

a

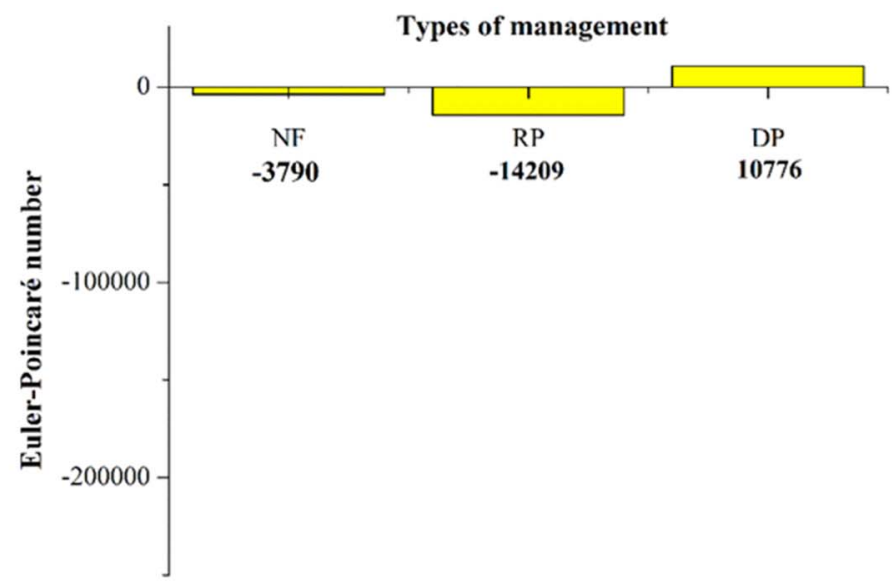

b

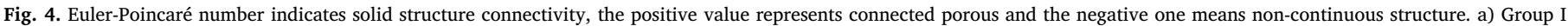

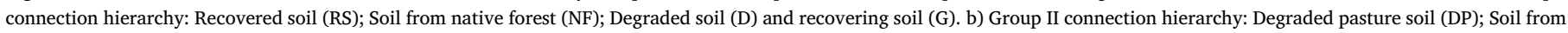
native forest (NF) and recovering pasture soil (RP).

arrangement, i.e., structurally, recovering pasture soil still does not present water content improvement. Notably, the small pores do not form a continuous network in this management type (Table 4).

\subsection{Euler-Poincaré number}

The Euler-Poincaré number extracted from the soil image can directly describe the connectivity relation of an object, which allows estimating how the solid and pore parts of soil behave. In other words, this parameter consistently indicates the effect of the management strategy in terms of the level of pore connectivity, i.e., revealing the effect of management practice on soil structure (Katuwal et al., 2015) by rapid image processing.

Group I (Fig. 4a): The results indicate that the solid structures of recovering soil and degraded soil are highly connected in comparison to those of soil from the native forest and recovered soil. From this result, we can deduce that these soils have similar compaction characteristics. The soil from the native forest and recovered soil exhibit more positive Euler-Poincaré numbers, i.e., the soils are more structured with pores that are more connected with each other. Conversely, recovering soil and degraded soil exhibit negative
Euler-Poincaré numbers, reflecting a large pore discontinuity, which is the result of intensive manipulation in the area. Consequently, a high number of micropores exist in these areas, as indicated by the results of the bulk density and total porosity.

Group II (Fig. 4b): The degraded pasture soil is the poorest in terms of solid structure connectivity when compared to soil from the native forest and recovering pasture soil. The degraded pasture soil group has a positive Euler-Poincaré number, which suggests that the pores are connected. The recovering pasture soil group and soil from the native forest have a negative Euler-Poincaré number, which suggests that the solid structure should be more spongy; however, the pores are more characterized by non-continuous quality than degraded pasture soil.

\subsection{Shannon entropy}

Shannon entropy $\mathrm{H}(\mathrm{x})$ quantifies uncertainty or disorder. Thus, this metric can be used to characterize each management type. The empirical frequency of the grayscale level can reflect the relationship between the porous and solid parts of a medium. Based on the frequency level, $\mathrm{H}(\mathrm{x})$ of the system can be obtained.

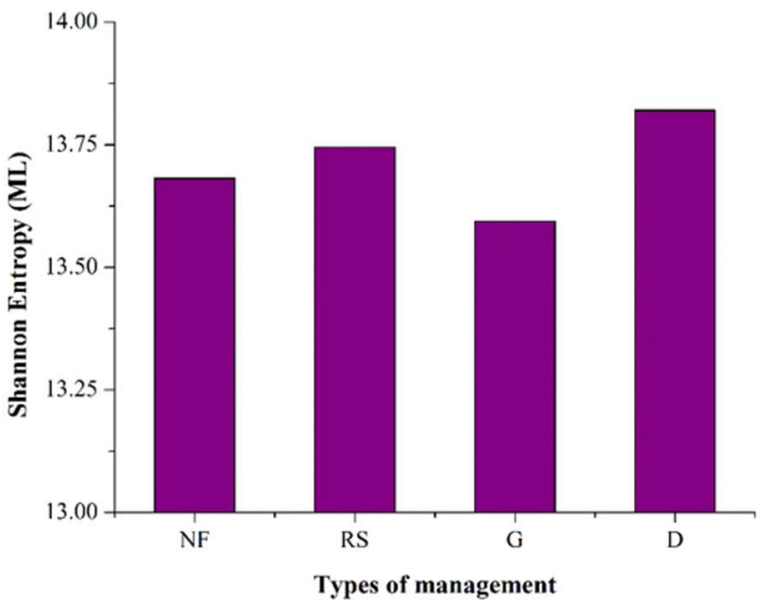

a

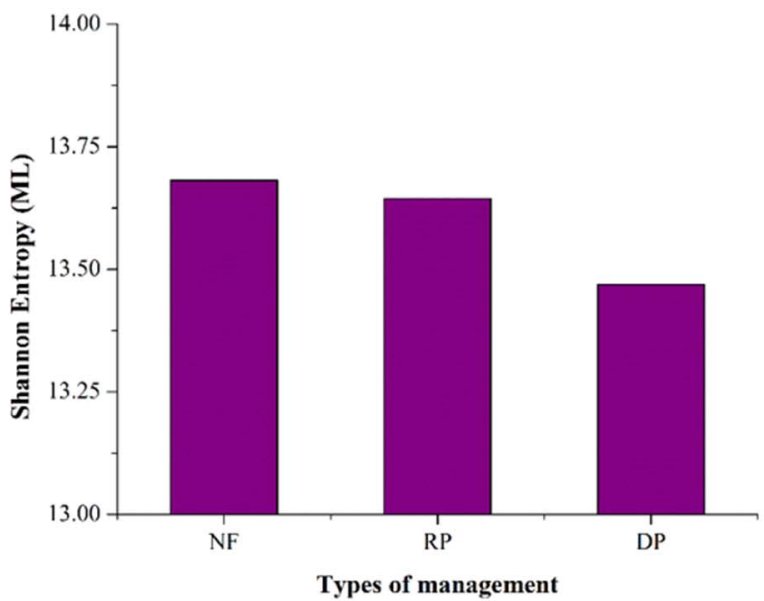

b

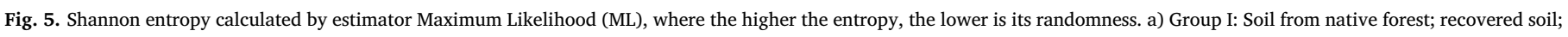
Recovering soil (G) and Degraded soil (D); b) Group II: Soil from native forest (NF); Recovering pasture soil (RP) and Degraded pasture soil (DP). 


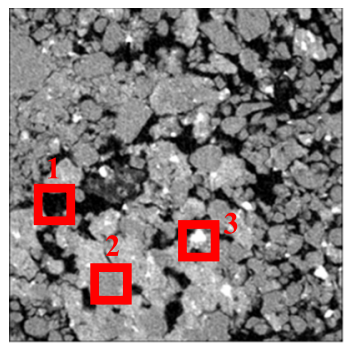

a

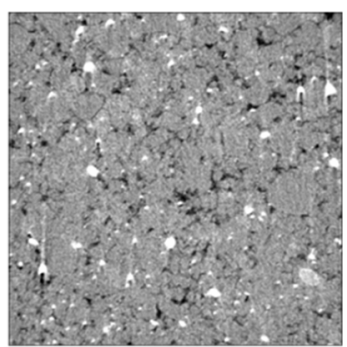

d

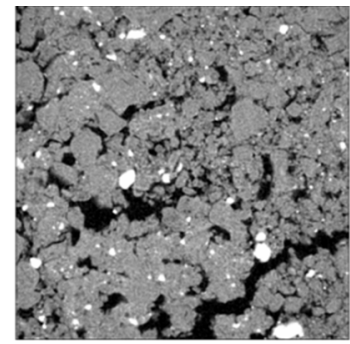

b

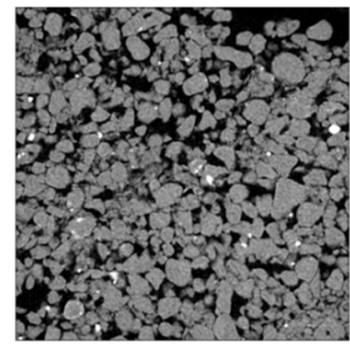

e

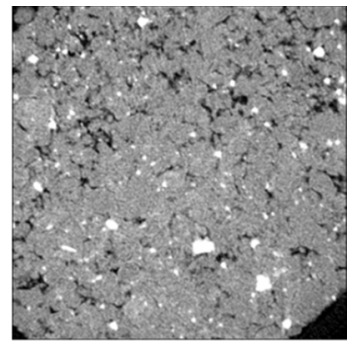

c

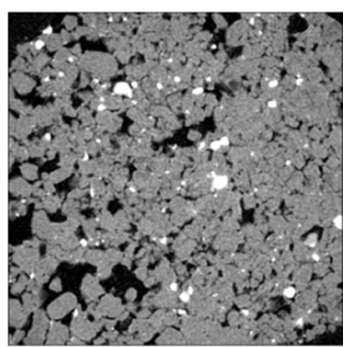

$\mathbf{f}$

Fig. 6. Microtomography in the transversal plane, black color represents pores space (1), gray color is solid part (2) and white color is iron or aluminum oxides (3) - a) Soil from native forest; b) Recovered soil; c) Recovering soil; d) Degraded soil; e) Recovering pasture soil; f) Degraded pasture soil.

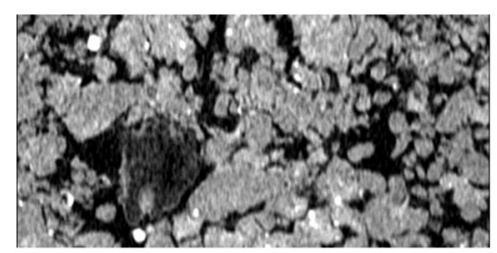

a

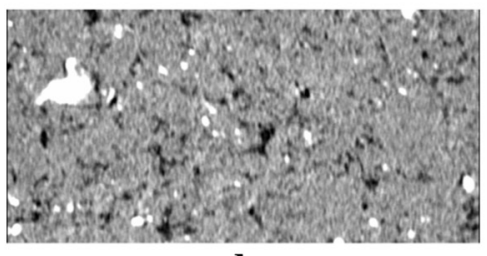

d

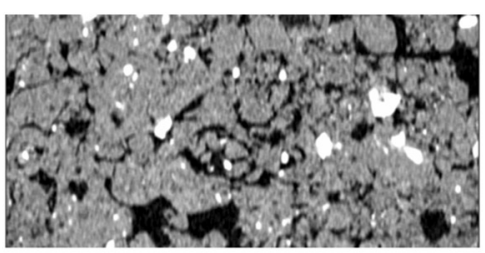

b

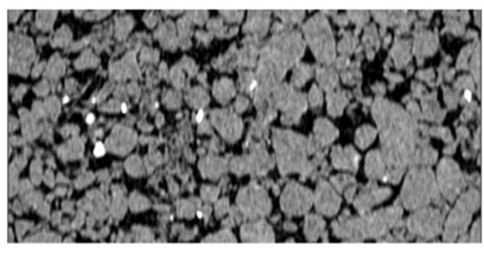

$\mathbf{e}$

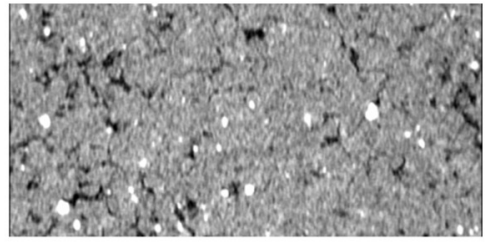

c

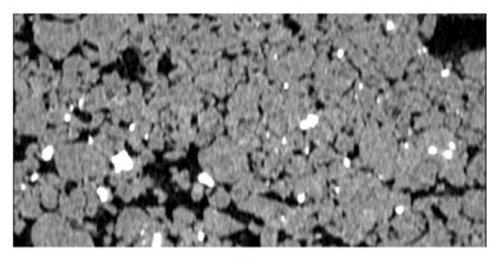

f

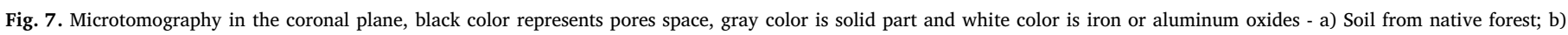
Recovered soil; c) Recovering soil; d) Degraded soil; e) Recovering pasture soil; f) Degraded pasture soil.

Group I (Fig. 5a): The hierarchy of this group differs from that of other groups. Degraded soil and recovered soil were characterized by high values of entropy, i.e., low randomness compared to soil from the native forest and recovering soil. This result is related to aggregate stability, which affects the system sensitivity in relation to the external environment.

Group II (Fig. 5b): Soil from the native forest exhibited the highest entropy when compared to recovering pasture soil and degraded pasture soil. Thus, the soil from the native forest system is more stable than other management types in this group.

\subsection{Soil structure visualization}

Based on 500 tomographic images, a series of important management information was extracted along transverse, coronal and sagittal planes. In the transverse plane (Fig. 6), soil from the native forest (Fig. 6a) was characterized by its heterogeneity, i.e., diverse distributions of aggregate and pore sizes, and recovered soil (Fig. 6b) exhibited similar characteristics. Recovering soil (Fig. 6c) was similar to degraded soil (Fig. 6d), and degraded soil was mainly homogeneous, which is typical of high compaction. In recovering pasture soil (Fig. 6e), the initial stages of recuperation are similar to those of soil from the native forest. Degraded pasture soil (Fig. 6f) is characterized by an agglomeration of aggregates typical of degraded soil.

The coronal and sagittal planes (Fig. 7) have similar characteristics; thus, they were analyzed together in this case. Soil from the native forest (Fig. 7a) demonstrated a high connectivity between pores, which is related to hydraulic/gaseous conductivity and thus to the capacity of the soil to conduct; however, the exchange or movement depends on the gas or water gradient. Recovered soil (Fig. 7b) exhibited characteristics similar to those of soil from the native forest; however, in terms of the porous connections and distribution of aggregates sizes, the properties of recovered soil were inferior to those of soil from the native forest. Recovering soil (Fig. 7c) and degraded soil (Fig. 7d) clearly displayed aggregate compaction because both management types are more anisotropic, i.e., the flux tends to be horizontal, which is a signal of compaction; however, based on software analysis, some macropores were likely present. Recovering pasture soil (Fig. 7e) exhibited a high aggregate content, but most aggregates were fragmented, which hampered water retention. Finally, degraded pasture soil (Fig. 7f) exhibited physical characteristics similar to those of degraded soil; however, more fragmented elements were observed in degraded pasture soil due 


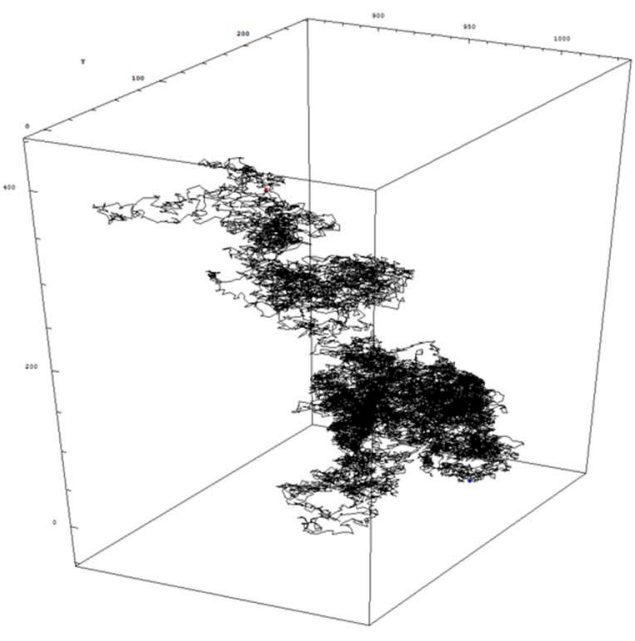

(a)

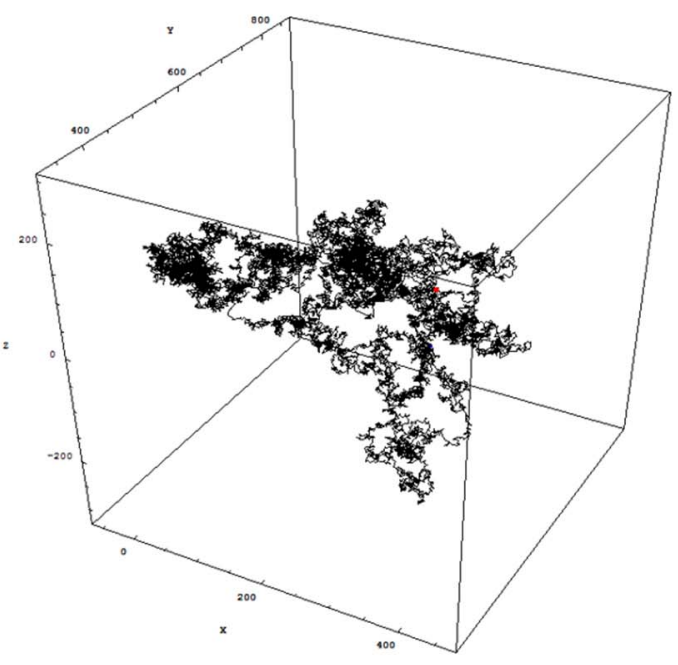

(c)

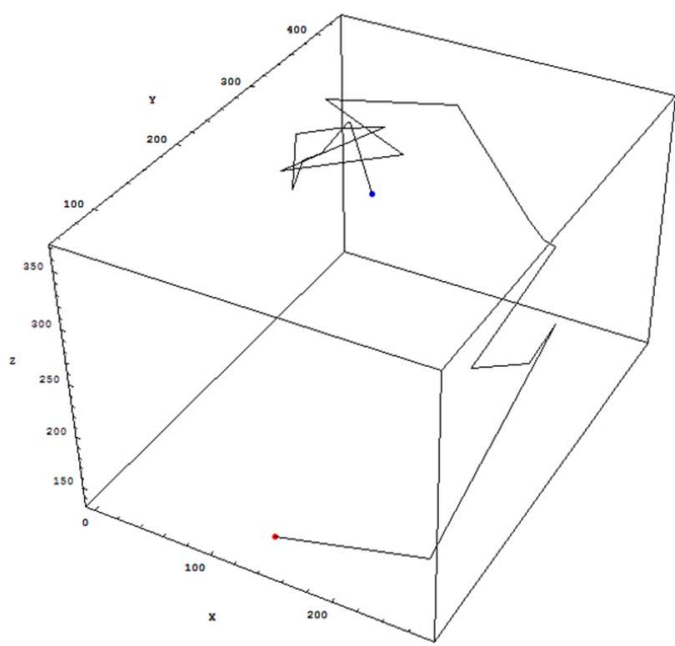

(b)

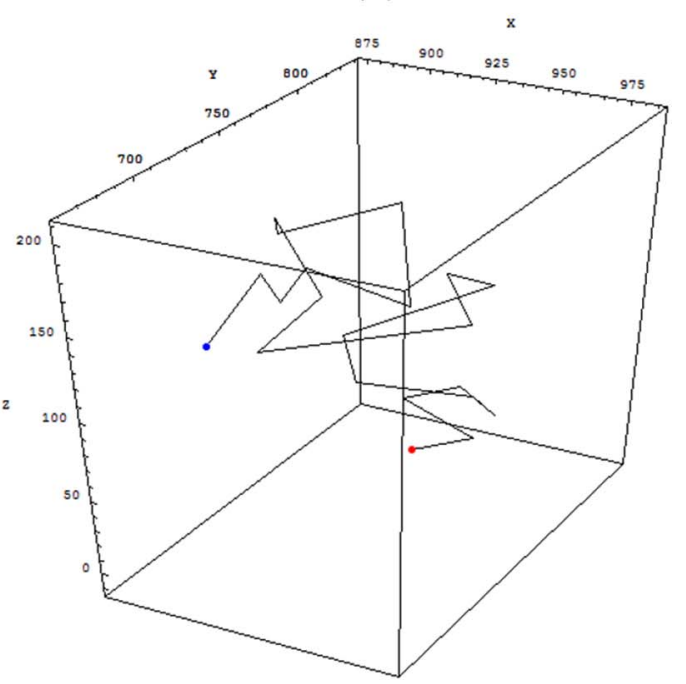

(d)

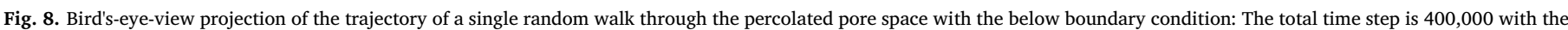

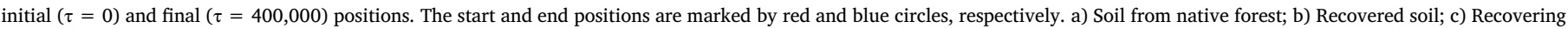
soil; d) Degraded soil. (For interpretation of the references to color in this figure legend, the reader is referred to the web version of this article.)

to the remaining roots.

\subsection{Water movement pathways in three-dimensional simulations}

The results from tomographic images for the three different planes were used in a 3D random walk model to simulate percolation in porous soil from the static situation.

Group I (Fig. 8): Out of all the managed soils, the soil from the native forest exhibited the highest total porosity. This result is an indication of the drainage conditions in the soil. However, this soil does not have high connectivity, as indicated by the Euler-Poincaré number, and it is a generally isotropic soil, i.e., this soil has a considerable number of macropores. Hence, this soil is expected to present high drainage (Table 5).

The total porosity of recovered soil is similar to that of soil from the native forest, as are its drainage quality and available water capacity. However, based on the positive Euler-Poincaré number, the connectivity of recovered soil is much lower than that of soil from the native forest and other types of managed soils. Although the degree of
Table 5

Information about water in soil - Group I.

\begin{tabular}{lllll}
\hline Sample type & NF & RS & G & D \\
\hline$\theta_{\text {pmp }}\left(\mathrm{cm}^{3} / \mathrm{cm}^{3}\right) \%$ & 22 & 19 & 16 & 19 \\
$\theta_{\mathrm{cc}}\left(\mathrm{cm}^{3} / \mathrm{cm}^{3}\right) \%$ & 26 & 24 & 22 & 24 \\
AWC $\left(\mathrm{cm}^{3} / \mathrm{cm}^{3}\right) \%$ & 4 & 5 & 6 & 5 \\
\hline
\end{tabular}

$\theta_{\mathrm{pmp}}$ : permanent wilting point; $\theta_{\mathrm{cc}}$ : field capacity; AWC: available water capacity; NF: soil from native forest; RS: recovered soil; G: recovering soil; D: degraded soil.

anisotropy of recovered soil is close to that of soil from the native forest, the percolation path is simplified by the pores (Fig. 8b), thereby providing a higher water retention capacity than soil from the native forest (Table 5).

According to the porosity results obtained by microtomography, the recovering soil exhibited the presence of remaining roots, which later became macropores, related to water drainage. The Euler-Poincaré number suggests that the soil is characterized by high structural connectivity; consequently, the pore structure is likely anisotropic, reflecting the random nature of the pore percolation network (Fig. 8c). In 


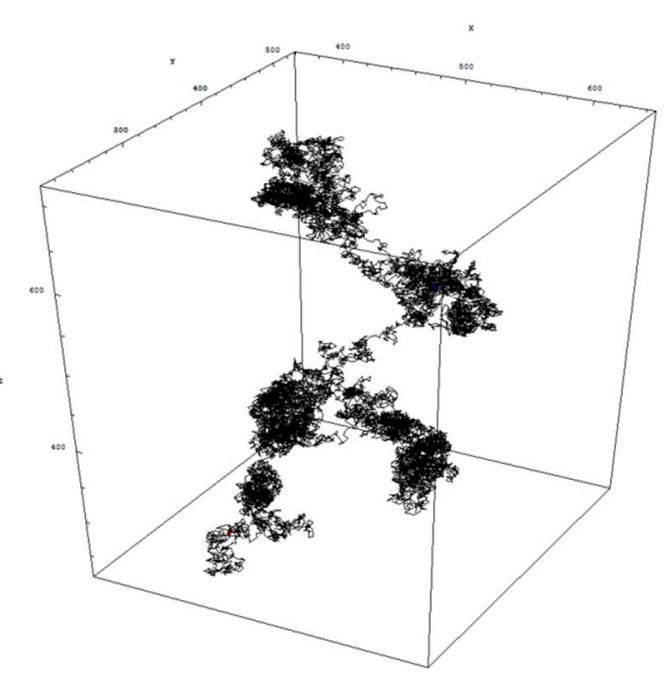

(a)

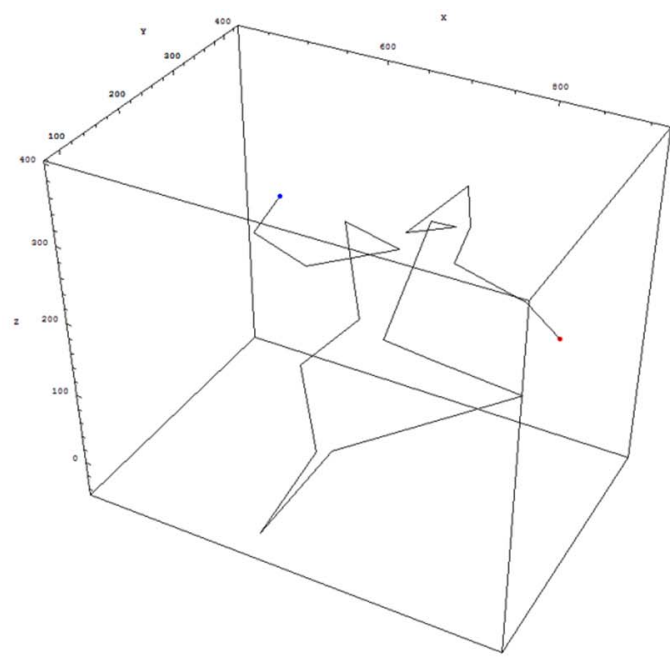

(b)

Fig. 9. Bird's-eye-view projection of the trajectory of a single random walk through the percolated pore space - a) Recovering pasture soil; b) Degraded pasture soil.

addition, this type of management provided a large available water capacity (Table 5).

The high compaction of degraded soil is a direct reflection of its total porosity. However, degraded soil has a geometric structure and elevated connectivity between pores, which creates a high degree of anisotropy. The pore percolation network is a simple, long, and connected pathway due to its compact nature (Fig. 8d); therefore, the degraded soil has a high water retention capacity (Table 5).

Group II (Fig. 9): In general, recovering pasture soil shows signs of the beginning of recuperation. It is clear that the negative connectivity of the recovering pasture soil is similar to the geometric characteristics of the soil from the native forest. Similarly, the connectivity of the degree of anisotropy soil is similar to that of soil from the native forest. Consequently, the recovering pasture soil displays random properties similar to those of soil from the native forest along the three axes in the simulation (Fig. 9a). However, recovering pasture soil has the capacity to deliver more water than soil from the native forest due to its morphometric similarity to degraded pasture soil (Table 6).

The degraded pasture soil exhibited clear signs of compaction. Additionally, the Euler-Poincaré number of the soil is positive; thus, it lacks dense connections. This result showed that the soil has isotropic characteristics, which lead to long and simplified percolation paths. In other words, there are connections between the small pores (Fig. 9b) that facilitate soil water availability (Table 6).

\section{Conclusion}

The aim of this study was to use unconventional methods to evaluate the physical soil structure and to simulate water movement pathways in three dimensions through X-ray microtomography. The S

Table 6

Information about water in soil - Group II.

\begin{tabular}{llll}
\hline Sample type & NF & RP & DP \\
\hline$\theta_{\text {pmp }}\left(\mathrm{cm}^{3} / \mathrm{cm}^{3}\right) \%$ & 22 & 10 & 8 \\
$\theta_{\mathrm{cc}}\left(\mathrm{cm}^{3} / \mathrm{cm}^{3}\right) \%$ & 26 & 16 & 13 \\
AWC $\left(\mathrm{cm}^{3} / \mathrm{cm}^{3}\right) \%$ & 4 & 6 & 5
\end{tabular}

$\theta_{\mathrm{pmp}}$ : permanent wilting point; $\theta_{\mathrm{cc}}$ : field capacity; AWC: available water capacity; NF: soil from native forest; RP: recovering pasture soil; PD: degraded pasture soil. index was used as an indicator to characterize the management structure condition. However, to minimize possible interpretation errors, other physical and structural parameters should be used based on the background of each management area. The Euler-Poincaré number indicates the connectivity of pores and can be used to determine the percolation paths and degree of anisotropy of each management type. The degree of anisotropy is an excellent indicator of spatial alignment within an image. The Shannon entropy reflects the management stability based on the relationship with the environment. The Arya and Paris model provided information on the water behavior in each type of managed soil, which was confirmed by the similarity between the physical parameters of this study in different soil planes and 3D simulations of water movement pathways. In conclusion, the physical and structural soil parameters and simulated water movement pathways effectively characterized the soil architecture of each sample. These results suggest the possibility of associating the soil structure with water movement in the soil and can be used to better understand soilwater synergy under different conditions.

\section{References}

Andrade, R.D.S., Stone, L.F., 2009. Índice S como indicador da qualidade física de solos do cerrado brasileiro. Rev. Bras. Eng. Agríc. Ambient. 13 (4), 382-388.

Appoloni, C.R., Cesareo, R., 1994. Microscanning and microtomography with X-ray tubes. In: Internal Report. 04-1994. CISB (University of Rome), pp. 1-83.

Arya, L.M., Paris, J.F., 1981. A physicoempirical model to predict the soil moisture characteristic from particle-size distribution and bulk density data. Soil Sci. Soc. Am. J. 45 (6), 1023-1030.

Beraldo, J.M.G., Scannavino Junior, F.A., Cruvinel, P.E., 2014. Application of X-ray computed tomography in the evaluation of soil porosity in soil management systems. Eng. Agric. Jaboticabal 34, 1162-1174.

Berkowitz, B., Ewing, R.P., 1998. Percolation theory and network modeling applications in soil physics. Surv. Geophys. 19, 23-72.

Bottinelli, N., Zhou, H., Boivin, P., Zhang, Z.B., Jouquet, P., Hartmann, C., Peng, X., 2016 Macropores generated during shrinkage in two paddy soils using X-ray micro-computed tomography. Geoderma 265, 78-86.

Brunsell, N.A., 2010. A multiscale information theory approach to assess spatial-temporal variability of daily precipitation. J. Hydrol. 385 (1), 165-172.

Carducci, C.E., Oliveira, G.C.D., Zeviani, W.M., Lima, V.M., Serafim, M.E., 2013. Bimodal pore distribution on soils under conservation management system for coffee crop. Eng. Agríc. 33 (2), 291-302.

Crestana, S., Mascarenhas, S., Pozzi-Mucelli, R.S., 1985. Statical and dynamical three dimensional studies of water in soil using computed tomography scanning. Soil Sci. 140, 326-332.

CT-Analyser, 2013. Retrieved from. http://bruker-microct.com/next/CTan_UserManual. pdf.

Dexter, A.R., 2004. Soil physical quality: part I. Theory, effects of soil texture, density, and organic matter, and effects on root growth. Geoderma 120 (3), 201-214.

Embrapa Solos, 2013. Sistema Brasileiro de Classificação de Solos, 3th edn. Centro Nacional de Pesquisa de Solos, Rio de Janeiro. 
Gaur, N., Mohanty, B.P., 2013. Evolution of physical controls for soil moisture in humid and subhumid watersheds. Water Resour. Res. 49 (3), 1244-1258.

Hainsworth, J.M., Aylmore, L.A.G., 1983. The use of computer-assisted tomography to determine spatial distribution of soil water content. Aust. J. Soil Res. 21, 435-443.

Harrigan, T.P., Mann, R.W., 1984. Characterization of microstructural anisotropy in orthotropic materials using a second rank tensor. J. Mater. Sci. 19, 761-767.

Hausser, J., Strimmer, K., Strimmer, M.K., 2012. Package 'Entropy'.

Hernández Zubeldia, E., de S. M. Ozelim, L.C., Luís Brasil Cavalcante, A., Crestana, S., 2015. Cellular automata and X-ray microcomputed tomography images for generating artificial porous media. Int. J. Geomech. 16 (2), 04015057.

Katuwal, S., Norgaard, T., Moldrup, P., Lamandé, M., Wildenschild, D., de Jonge, L.W. 2015. Linking air and water transport in intact soils to macropore characteristics inferred from X-ray computed tomography. Geoderma 237, 9-20.

Macedo, A., 2003. Validação de um analisador granulométrico automático em 3 laboratórios de análise de solos do Brasil. In: Congresso Brasileiro de Ciência do Solo. vol. 29.

Manieri, J.M., Vaz, C.M.P., De Maria, I.C., 2007. TDR spiral probe for moisture measurement in the soil profile. Revista Brasileira De Ciencia Do Solo 31 (2), 191-198.

Marchini, D.C., Ling, T.G.C., Alves, M.C., Crestana, S., Souto Filho, S.N., Arruda, O.G., 2015. Matéria orgânica, infiltração e imagens tomográficas de Latossolo em recuperação sob diferentes tipos de manejo. Rev. Bras. Eng. Agríc. Amb. 19, 574-580.

Martínez, F.S.J., Ortega, F.M., Monreal, F.C., Kravchenko, A.N., Wang, W., 2015. Soil aggregate geometry: measurements and morphology. Geoderma 237, 36-48.

Moncada, M.P., Ball, B.C., Gabriels, D., Lobo, D., Cornelis, W.M., 2015. Evaluation of soil physical quality index S for some tropical and temperate medium-textured soils. Soil Sci. Soc. Am. J. 79 (1), 9-19.

Naime, J.M., Vaz, C.M.P., Macedo, A., 2001. Automated soil particle size analyzer based on gamma-ray attenuation. Comput. Electron. Agric. 31, 295-304.

Naime, J.D.M., Shinya, V., Vaz, C., 2004. Programa para Estimativa Indireta da Curva de Retenção da Água no Solo. Embrapa Instrumentação Agropecuária, Comunicado Técnico.

Nakashima, Y., Kamiya, S., 2007. Mathematica programs for the analysis of three-dimensional pore connectivity and anisotropic tortuosity of porous rocks using X-ray computed tomography image data. J. Nucl. Sci. Technol. 44, 1233-1247.

Nakashima, Y., Nakano, T., 2012. Steady-state local diffusive fluxes in porous geo-materials obtained by pore-scale simulations. Transp. Porous Media 93, 657-673.

NRcon User Manual, 2016. July, Retrieved from. http://bruker-microct.com/next/ NReconUserGuide.pdf.

Odgaard, A., 1997. Three-dimensional methods for quantification of cancellous bone architecture. Bone 20 (4), 315-328.

Onody, R.N., Posadas, A.N.D., Crestana, S., 1995. Experimental studies of the fingering phenomena in two dimensions and simulation using a modified invasion percolation model. J. Appl. Phys. 78, 2970-2976.

Otsu, N., 1975. A threshold selection method from gray-level histograms. Automatica 11,
$23-27$

Passoni, S., Borges, F.D.S., Pires, L.F., Saab, S.D.C., Cooper, M., 2014. Software image J to study soil pore distribution. Cienc. Agrotecnol. 38 (2), 122-128.

Petrovic, A.M., Siebert, J.E., Rieke, P.E., 1982. Soil bulk density analysis in three dimensions by computed tomographic scanning. Soil Sci. Soc. Am. J. 46 (3), 445-450.

Rozenbaum, O., Bruand, A., Le Trong, E., 2012. Soil porosity resulting from the assemblage of silt grains with a clay phase: new perspectives related to utilization of X-ray synchrotron computed microtomography. Compt. Rendus Geosci. 344, 516-525.

Shannon, C.E., 2001. A mathematical theory of communication. ACM SIGMOBILE Mob. Comput. Commun. Rev. 5 (1), 3-55.

Skyscan, 2015. Morphometric parameters measured by Skyscan ${ }^{\mathrm{TM}}$ CTanalyser software. http://bruker-microct.com/next/CTAn03.pdf, Accessed date: 28 June 2016.

Tomasella, J., Hodnett, M.G., Rossato, L., 2000. Pedotransfer Functions for the Estimation of Soil Water Retention in Brazilian Soils.

van Genuchten, M.T., 1980. A closed-form equation for predicting the hydraulic conductivity of unsaturated soils. Soil Sci. Soc. Am. J. 44, 892-898.

van Lier, J., 2014. Revisiting the S-index for soil physical quality and its use in Brazil. Rev. Bras. Ciênc. Solo 38 (1), 1-10.

Varandas, J.M.M., 2011. Avaliação da qualidade física do solo em uma escala de microbacia (Doctoral dissertation). Centro de Energia Nuclear na Agricultura, Piracicaba, SP, Brazil.

Vaz, C.M.P., Iossi, M., Naime, J., Silva, A., 2003. Retenção de água no solo estimada através da medida de distribuição do tamanho das partículas do solo. Embrapa Instrumentação Agropecuária-Comunicado Técnico (INFOTECA-E).

Vaz, C.M.P., de Freitas Iossi, M., de Mendonça Naime, J., Macedo, A., Reichert, J.M., Reinert, D.J., Cooper, M., 2005. Validation of the Arya and Paris water retention model for Brazilian soils. Soil Sci. Soc. Am. J. 69, 577-583.

Vaz, C.M.P., De Maria, I.C., Lasso, P.O., Tuller, M., 2011. Evaluation of an advanced benchtop micro-computed tomography system for quantifying porosities and poresize distributions of two Brazilian Oxisols. Soil Sci. Soc. Am. J. 75, 832-841.

Vogel, H.J., 1997. Morphological determination of pore connectivity as a function of pore size using serial sections. Eur. J. Soil Sci. 48, 365-377.

Vogel, H.J., 2002. Topological characterization of porous media. In: Morphology of Condensed Matter. Springer, Berlin Heidelberg, pp. 75-92.

Vogel, H.J., Roth, K., 2001. Quantitative morphology and network representation of soil pore structure. Adv. Water Resour. 24, 233-242.

Wu, Y., Zhou, Y., Saveriades, G., Agaian, S., Noonan, J.P., Natarajan, P., 2013. Local Shannon entropy measure with statistical tests for image randomness. Inf. Sci. 222, $323-342$.

Zaslavsky, D., Rogowski, A.S., 1969. Hydrologic and morphologic implications of anisotropy and infiltration in soil profile development. Soil Sci. Soc. Am. J. 33 (4), 594-599.

Zeviani, W.M., 2013. Parametrizações Interpretáveis em Modelos Não Lineares (Doctoral dissertation). Universidade Federal de Lavras, Lavras, MG, Brazil. 